\title{
Hacia una gestión de las aguas urbanas basada en la naturaleza
}

Se ha desarrollado el tema de infraestructura verde y azul, que representa la incorporación de

soluciones basadas en la naturaleza para la gestión hídrica

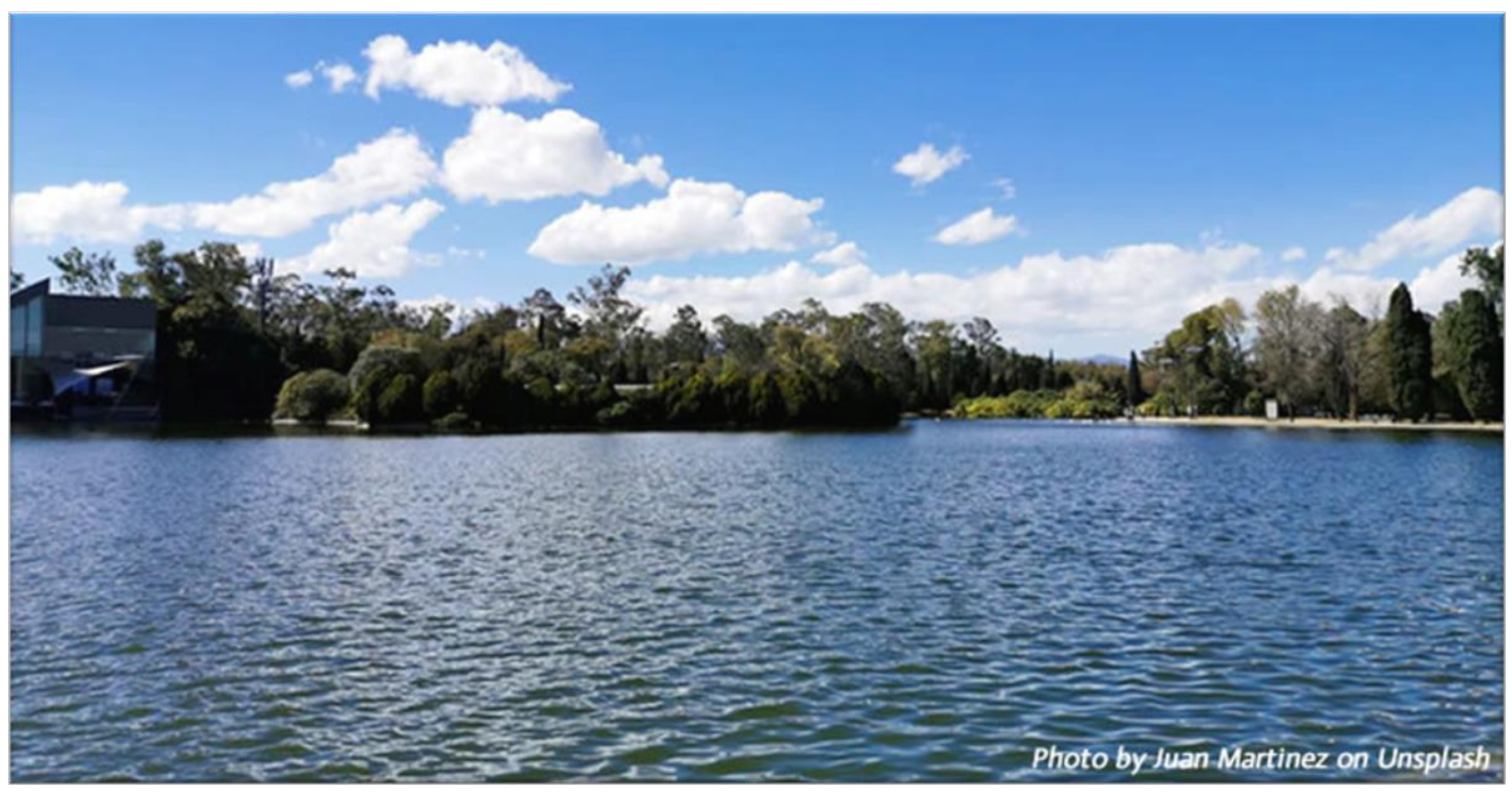

Desde que el ser humano comenzó a construir ciudades, hace más de cinco milenios, creó sistemas para drenar las aguas urbanas (Viyogi 1984).

Sin embargo, los principios rectores del diseño de los sistemas actuales tienen sus orígenes en el movimiento higienista de la mitad del siglo XIX (Bertrand-Krajewski, 2005). Durante la segunda parte de este mismo siglo se desarrollaron los principios básicos que todavía rigen el diseño del drenaje urbano en México: las aguas pluviales constituyen un problema y deben evacuarse lejos de la ciudad lo más rápidamente posible. En aquel entonces, el enfoque era meramente hidráulico e ingenieril, y el principal reto era el dimensionamiento de las tuberías necesarias para evacuar las aguas de la manera más eficiente.

La urbanización galopante del siglo XX hizo que las redes de drenaje diseñadas en las décadas anteriores colapsaran, causando inundaciones más frecuentes. La respuesta fue construir obras cada vez más grandes. Por los años setenta comenzó a ser claro que este enfoque había llegado a sus límites, por múltiples razones. Primero, la económica, pues el costo del manejo de las aguas pluviales por estas grandes obras se había encarecido cada vez más. También, los sistemas de redes de drenaje habían 
modificado el equilibrio hidrológico de las cuencas, creando problemas colaterales. Un ejemplo de estos efectos negativos es el sistema de drenaje de la zona metropolitana del valle de México. Las aguas que precipitan en la cuenca del valle de México, y que antiguamente se escurrían hasta el lago de Texcoco, ahora son evacuadas por una serie de túneles y canales hasta el valle del Mezquital, contribuyendo tanto a la reducción de la recarga de los acuíferos de la cuenca del valle de México, como a la desaparición del lago.

Por estas razones se desarrollaron en la segunda parte del siglo XX metodologías que incluyen medidas destinadas a retener el agua en dónde se precipita, y así reducir los escurrimientos y las inundaciones. Estas acciones tienen varios nombres, según el país dónde se desarrollaron: Sistemas de Drenaje Urbano Sostenible (SUDS), en el Reino Unido; Mejores Prácticas de Manejo (BMP) o Desarrollo de Bajo Impacto (LID), en Estados Unidos; Técnicas Alternativas para la gestión del agua pluvial (Techniques alternatives), en Francia, etc. (Fletcher et al., 2015). Este concepto de la gestión de aguas pluviales ya está bien implantado en Europa o Estados Unidos, y comienza ya a implementarse también en México. Un ejemplo se encuentra en la Ley del Agua para el Estado de Jalisco y sus Municipios, la cual, en su artículo 86-bis, impone la retención de las aguas pluviales en el predio de desarrollo. Esto busca el llamado impacto hidrológico cero, que define que el gasto de escurrimiento pico del predio impermeabilizado no debe ser superior al gasto de la parcela en su estado natural. Las medidas técnicas para llegar a este objetivo pueden tomar varias formas, ya sea en obras grises o verdes, tales como lagunas de retención, azoteas verdes, biozanjas, etc.

Cabe mencionar que además de disminuir la posibilidad de inundaciones, la retención de las aguas de escurrimiento en el predio tiene el efecto secundario de ayudar en el tratamiento de las aguas pluviales, pues las aguas de origen pluvial, al contrario de las creencias comunes, pueden estar altamente contaminadas, especialmente en zonas urbanas (Philippe et Ranchet, 1987; Ellis, 1991; Chocat et al., 1992; Bachoc et al., 1992.). Se ha estimado que el agua de lluvia recoge del 20 al 25 \% de su contaminación por el simple hecho de atravesar la atmósfera (Battaglia et al., 2003). Al escurrirse en los techos y calles, el agua pluvial se contamina aún más. Afortunadamente, la mayoría de esta contaminación está fijada en sólidos en suspensión, lo que facilita el tratamiento por simple decantación, que puede alcanzar tazas de tratamiento desde el 50 hasta el 95 \%, según los contaminantes (Battaglia et al. 2003). Así, las técnicas de retención del agua en el predio, por su acción de decantación y filtración, apoyan en la reducción de la contaminación que llegaría a los ríos y lagos, además de facilitar su reúso. De esta manera, el agua pluvial que se consideraba un problema se convierte en un recurso.

En las últimas décadas se ha desarrollado el tema de infraestructura verde y azul, que representa la incorporación de soluciones basadas en la naturaleza para la gestión hídrica. Estas soluciones tienen muchos beneficios, además de la gestión hídrica, tales como el uso social y cultural, el control de la temperatura, la provisión de refugios a fauna y flora, etc. (Bertrand-Krajewski, 2020). En este contexto, la gestión del agua urbana no solamente es el coto privado de los ingenieros, sino también de los urbanistas, arquitectos, botanistas, biólogos, sociólogos y tomadores de decisiones, pues la ciudad se debe estudiar como un sistema complejo, en el cual el ser humano es protagonista. El agua no debe desconectarse del diseño y gestión de los asentamientos humanos.

Como hemos visto, la gestión de las aguas pluviales urbanas no es un tema estático. En México tenemos el deber de acompañar esta evolución para que su manejo deje de ser un tema visto solamente desde un punto de vista ingenieril, y avance hacia una gestión integral, más respetuosa tanto de los ecosistemas como de los habitantes de las ciudades. Ese trabajo debe abordarse desde los ejes de la 
PERSPECTIVAS IMTA (0)

$N^{\circ} .06,2021$

Autor: Laurent Guillaume Courty

DOI: doi.org/10.24850/b-imta-perspectivas-2021-06

política pública, la educación y la sensibilización de los tomadores de decisiones, así como del público en general.

\section{Referencias:}

A. Bachoc, G. Chebbo y J. Mouchel : La pollution des rejets pluviaux urbains : son importance, ses caractéristiques, quelques éléments sur ses origines et son interception. Rejets urbains par temps de pluie : pollution et nuisances, páginas 9-21, 1992.

Battaglia, P., Chocat, B., Blanchard, M., y otros. (2003). La Ville et son assainissement (B. Chocat, M. Blanchard, H. Bouillon, B. Guézo, O. Norotte, \& R. Thomazeau [eds.]. Cerema.

Bertrand-Krajewski, J. L. (2005, diciembre). Sewer systems in the 19th century; diffusion of ideas and techniques, circulation of engineers. En Proceedings of the 4th Conference of the International Water History Association (IWHA), París, Francia (pp. 1-4).

Bertrand-Krajewski, J. L. (2020). Integrated urban stormwater management: Evolution and multidisciplinary perspective. Journal of Hydro-environment Research.

B. Chocat: Pollution due to urban stormwater discharges: 37 pages, 6 figures and 17 tables to begin to explain. Provisory report, INSA, Lyon, Francia, septiembre 1992, 37 p, 1992.

J.B. Ellis: Measures for the control and treatment of urban runoff quality. Middlesex Polytechnic, 1991.

Fletcher, T. D., Shuster, W., Hunt, W. F., Ashley, R., Butler, D., Arthur, S., ... \& Viklander, M. (2015). SUDS, LID, BMPs, WSUD and more-The evolution and application of terminology surrounding urban drainage. Urban water journal, 12(7), 525-542.

J.P. Philippe y J. Ranchet: Pollution des eaux de ruissellement pluvial en zone urbaine : synthèse des mesures sur dix bassins versants en région parisienne. Laboratoire central des ponts et chaussées, 1987.

Photo by Juan Martinez on Unsplash 